\title{
Instrumental and Sensory Approaches for the Characterization of Compounds Responsible for Wine Aroma
}

\author{
by Jean-Christophe Barbe ${ }^{* a}$ ), Bénédicte Pineau $\left.{ }^{\mathrm{b}}\right)$, and Antonio Cesar Silva Ferreira ${ }^{\mathrm{c}}$ ) \\ a) Institut des Sciences de la Vigne et du Vin, UMR 1219 Cnologie, ENITA de Bordeaux, 1, \\ Cours du général de Gaulle, CS 40201, F-33175 Gradignan Cedex \\ (phone: +33557353873; fax: +33557350739; e-mail: jc-barbe@enitab.fr) \\ b) Institut des Sciences de la Vigne et du Vin, UMR 1219 Enologie, Faculté d'Enologie, 351, \\ Cours de la Libération, F-33405 Talence Cedex \\ c) Escola Superior de Biotecnologia, Universidade Catolica Portuguesa, Rua Dr. Antonio Bernardino de \\ Almeida, P-4700-072 Porto
}

\begin{abstract}
More than 800 aromatic compounds have been identified in wine, some of them at the ng/l level. Wine, therefore, constitutes a very complex matrix, from which it is difficult to isolate a specific aroma character. Gas chromatography-olfactometry $(\mathrm{GC}-\mathrm{O})$ applied to wine extracts is used to characterize odor-active zones that are often treated in a hierarchical way by Aroma Extract Dilution Analysis (AEDA). The aromatic impact of the volatiles is evaluated, generally by determining perception thresholds. This methodology has provided convincing results concerning wine flavors, but it does have its limitations. For instance, data on $\beta$-damascenone have demonstrated that these methods could reach their limits for this volatile, in particular, because of the non-quantitative representation of aroma extracts of wines, and because of the difficulty to accurately determine the perception threshold in wines for a compound already present. For $\beta$-damascenone, we have shown that its very low detection threshold with $\mathrm{GC}-\mathrm{O}$, its wide range, and its dependence on the composition of the medium resulted in overestimating its direct impact on the aroma of wine. Another way to facilitate the characterization of aromatic compounds was, therefore, investigated. High-Performance Liquid Chromatography (HPLC) methods were developed for the analysis of wine extracts. From an aromatic extract, 25 fractions with various flavors were thus obtained, and reverse-phase methodology was used for the selection and characterization of red- and black-fruit aromas in red wines.
\end{abstract}

Introduction - Wine aroma is very complex. On one hand, it is the result of a long biological, biochemical, and technological sequence, and, on the other hand, it consists of several hundred volatiles. Concentrations of these compounds may vary from milligram to nanogram per liter. These substances are in a hydro-alcoholic solution containing other very abundant components. Wine, therefore, constitutes a very complex matrix, from which it is difficult to isolate a specific aroma character. Gas chromatography (GC) coupled with various detection systems proved to be adequate for analyzing aromatic wine extracts, generally obtained by liquid-liquid or liquidsolid extraction. Initially, gas chromatography-olfactometry $(\mathrm{GC}-\mathrm{O})$ is applied to wine extracts to characterize odor-active zones. In a second run, the aromatic impact of the volatiles identified is evaluated, generally by determining perception thresholds. This study deals with the impact of Sotolon in port wine and the role played by $\beta$ damascenone $(=(E)-1-(2,6,6$-trimethylhexa-1,3-dien-1-yl)but-2-en-1-one $)$ in a practi- 
cal demonstration of the methodology used to characterize compounds responsible for wine aromas, as well as the limitations of these methods.

The duration of the ageing process in the production of port has a fundamental role in determining the quality of the finished product. During this maturation period, wine undergoes a number of compositional changes which have major consequences on the color and aroma of the wine. The typical aroma developed during barrel storage is the consequence of this chemical behavior, and is usually described as 'maderized', 'rancio', 'burnt', 'dry fruit', 'nutty', and 'spicy'. Several GC-O procedures are available in the literature to rank substances according to their respective impact on the overall aroma of a foodstuff. They can be divided into the following categories: 1) dilution procedures like CHARM analysis [1] or Aroma Extract Dilution Analysis (AEDA) [2]; 2) Intensity measurement methods like hyphenated headspace-GC sniffing [3], or by frequency counting with scoring attribution [4].

The AEDA has been proven to be a very powerful technique for the screening of the impact of odor contributors to an aroma, and for the identification of molecules in several foods [5-9] and also in wine [10][11]. One aim of this study utilizing AEDA was the chemical characterization of port. There was particular emphasis on the volatile fraction allowing substances that have a large impact on the characteristic aroma of aged port wine to be identified.

$\beta$-Damascenone is a norisoprenoid with $13 \mathrm{C}$-atoms and was identified for the first time in 1975 in the essential oil of roses [12]. This compound has since been found in many drinks such as beer, coffee, and, of course, wine [13]. $\beta$-Damascenone has an aroma generally described as 'apple' [14][15] or 'baked apples' [16]. In olfactometry, using AEDA, $\beta$-damascenone is almost always systematically among the very few compounds with the highest dilution factor [14][16][17]. Due to this analytical characteristic and its high Odor Activity Value (OAV), $\beta$-damascenone is often described as being a major contributor to wine aroma. Nevertheless, literature data show a wide variation in perception thresholds for $\beta$-damascenone, ranging from $\mathrm{ng} / \mathrm{l}$ in $\mathrm{H}_{2} \mathrm{O}$ [18] to a few tens of $\mathrm{ng} / \mathrm{l}$ in synthetic media [19-21]. This threshold may reach a value between 4 and $7 \mu \mathrm{g} / \mathrm{l}$ in wine [16][22][23], where the average content is $c a .1$ to $1.5 \mu \mathrm{g} / 1$ [21][22][24]. These levels clearly raise the question whether $\beta$-damascenone really has a direct impact on wine flavor. In an attempt to answer this question, we first have studied the characteristics of $\beta$-damascenone (perception threshold, concentrations in red wines, and, consequently, OAV) in several red wines. We will then illustrate and explain the particular behavior of this compound in olfactometric analyses.

The Impact of Sotolon on the Aroma of Port Wine - Using the AFNOR NFV-09021 procedure, a selection of the more relevant descriptors related to the characterization of the typical aroma of aged port wine was carried out. The highest rating ones were 'glue solvent', 'dry fruit', 'spice-like', and 'nutty'.

$G C-O$ Results. The similarity test effectuated by the panel, between the wine and the respective organic extracts showed that the typical aroma of aged port was better represented in the $\mathrm{CH}_{2} \mathrm{Cl}_{2}$ extract. Hence, this solvent was chosen to perform the $\mathrm{GC}-$ $\mathrm{O}$ investigations. Sixteen odor-active zones were selected as the most frequently cited by the four members of the $\mathrm{GC}-\mathrm{O}$ panel. Of these, five showed aromas close to those descriptors selected as characteristic of oxidatively aged port wine. They were 
described as 'ethyl acetate glue' with a retention index (RI) of 1122, 'caramel candy' $(\mathrm{RI}=1138)$, 'roasted peanut' $(\mathrm{RI}=1312)$, 'burnt sugar' $(\mathrm{RI}=2030)$, and 'nut, spicy, old port wine, and burnt sugar' $(\mathrm{RI}=2172)$. The latter olfactory zone was considered as particularly intense and persistent, and, most importantly, the only one that closely matched one of the descriptors.

AEDA Results. AEDA was used as a 'screening methodology' and not as a quantification measure to evaluate and rank (by dilution factor (DF) values obtained) each of the six aromatic zones selected by $\mathrm{GC}-\mathrm{O}$ by their relative importance for further identification. The resulting 'aromagram' as well as the GC/MS chromatogram of a $\mathrm{CH}_{2} \mathrm{Cl}_{2}$ extract of a 60 -year-old wine, is shown in Fig. 1.

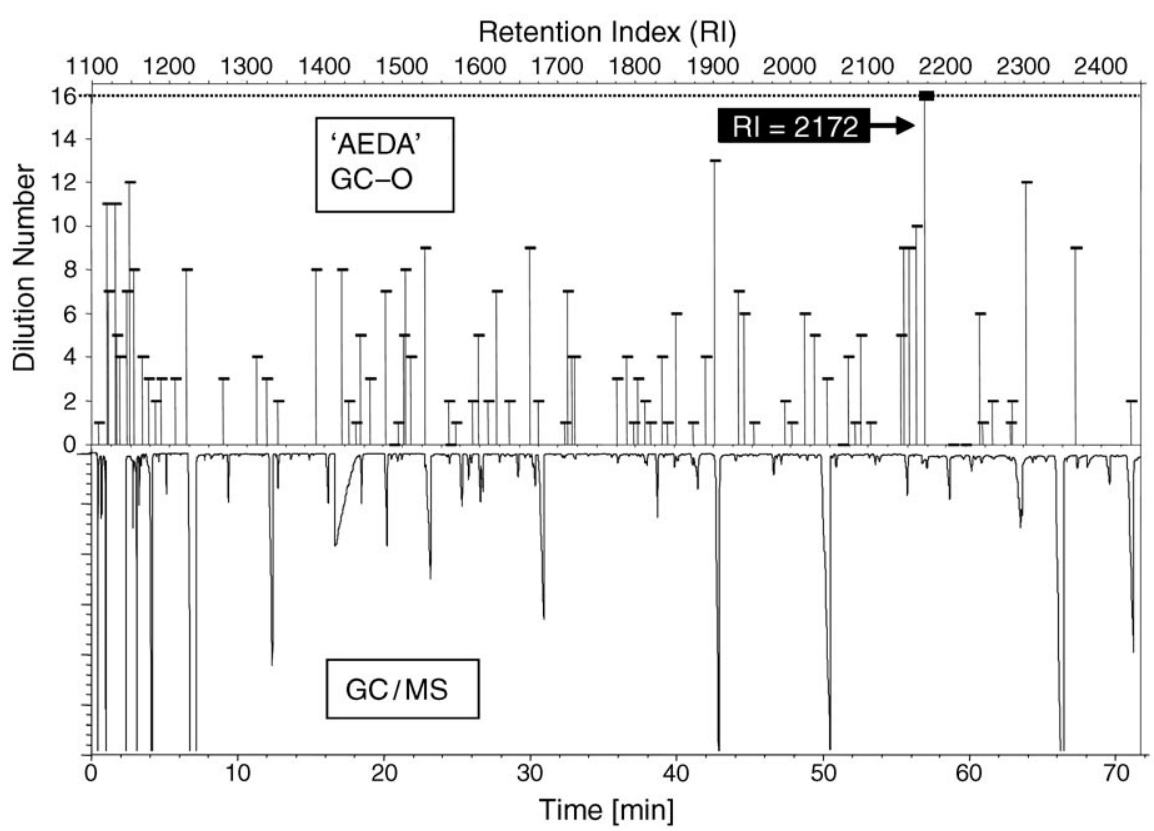

Fig. 1. Aromagram and chromatogram of a $\mathrm{CH}_{2} \mathrm{Cl}_{2}$ extract of a 60-year-old wine

The dilution factors observed for the five odor zones selected were 128, 32, 16, 32, and 65536, respectively, for the retention indices 1122 ('caramel candy'), 1138 ('roasted peanut'), 1312 ('roasted peanut'), 2030 ('roasted peanut'), and 2172 ('nut', 'spicy'). The last odor-active compound clearly prevailed over all the others with a particularly high dilution factor measured. Repetitions of AEDA of extracts obtained from other wines older than 40 years were in agreement with this last observation in that they all presented a higher DF for the $\mathrm{RI}=2172$ odor zone. As a result of these observations, all our efforts concentrated on the molecule(s) present in this zone.

Identification of Sotolon. The low-resolution mass spectrum (GC/LR-MS) of the retention-index-2172 fraction showed the same peaks, identical fragmentation, and relative abundances which were comparable to 3-hydroxy-3,4-dimethylfuran-2(5H)- 
one (as indexed in the NBS 75000 library). The interpretation of the spectrum was reported in [14]. Analyses carried out with a chemical-ionization mass spectrometry (GC/CI-MS) showed a basic peak with $m / z$ 146, which corresponds to $\left[M-\mathrm{NH}_{4}\right]^{+}$. This is in agreement with the relative acidity of this compound. High-resolution (HR) mass spectrometry confirmed our previous results, and, in view of the accuracy of the determinations, the fragment masses are completely in agreement with the suggested structure [25]. Moreover, the retention index of the reference compound was 2172 and 1066 for the FFAP and BP1 columns, respectively. These values were identical to those obtained for the wine extract and are in agreement with those reported in the literature [26]. Finally, by GC-O using the same operating conditions, it was verified that the 'aromatic quality' of the pure product was identical with that present in the wine extract.

Sotolon Levels in Wines. The concentrations of 3-hydroxy-4,5-dimethylfuran$2(5 H)$-one increase with length of storage from a few dozens $\mu \mathrm{g} / \mathrm{l}$ in young wines, to $c a$. $100 \mu \mathrm{g} / \mathrm{l}$ in ten-year-old wines, and reaches a maximum of $c a .200 \mu \mathrm{g} / \mathrm{l}$ after an additional ten years of oxidative ageing. The highest contents (almost $1 \mathrm{mg} / \mathrm{l}$ ) were observed for wines older than 50 years (Fig. 2).

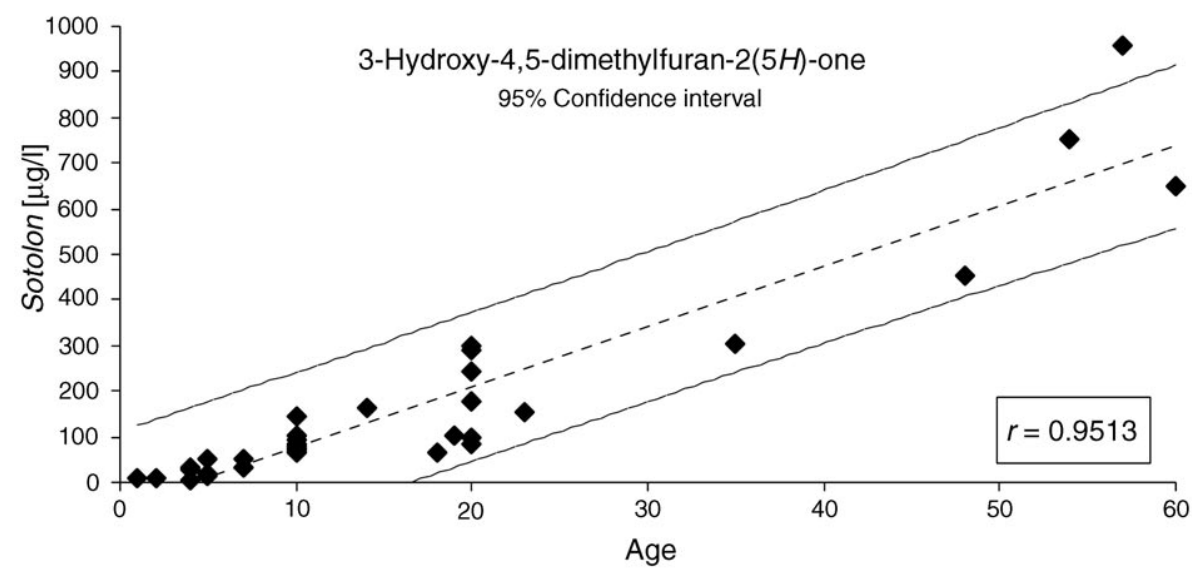

Fig. 2. Concentration of Sotolon observed in 'Colheita' category port wine $[\mu \mathrm{g} / \mathrm{l}]$

The high value of the correlated correlation coefficient $(r>0.95)$ clearly demonstrates the dependence of the Sotolon content upon the time of barrel ageing under oxidative conditions. This makes the molecule an 'age indicator'. The predictive precision for age estimation (age*) was calculated, by construction of the simple linear model $($ Age $*=5.67 \times[$ Sotolon $]+0.067)$ with a $95 \%$ of confidence interval being equal to eleven years. The rate of formation was approximately estimated (slope of linear model) at $6 \mu \mathrm{g} / \mathrm{l} / \mathrm{year}$.

Sensorial Impact. The flavor threshold of this compound was determined to be $19 \mu \mathrm{g} / \mathrm{l}$ in port wine. This result is in total agreement with data previously reported in $12 \%(v / v)$ hydro-alcoholic solution [27] and 'flor' sherry-type wine 'vin jaune' [28]. 
When considering the effect of Sotolon in port wine alone as expressed by the Odor Activity Value (OAV), it can be seen that Sotolon has a positive effect in wines close to ten years old as shown in Fig. 3 .

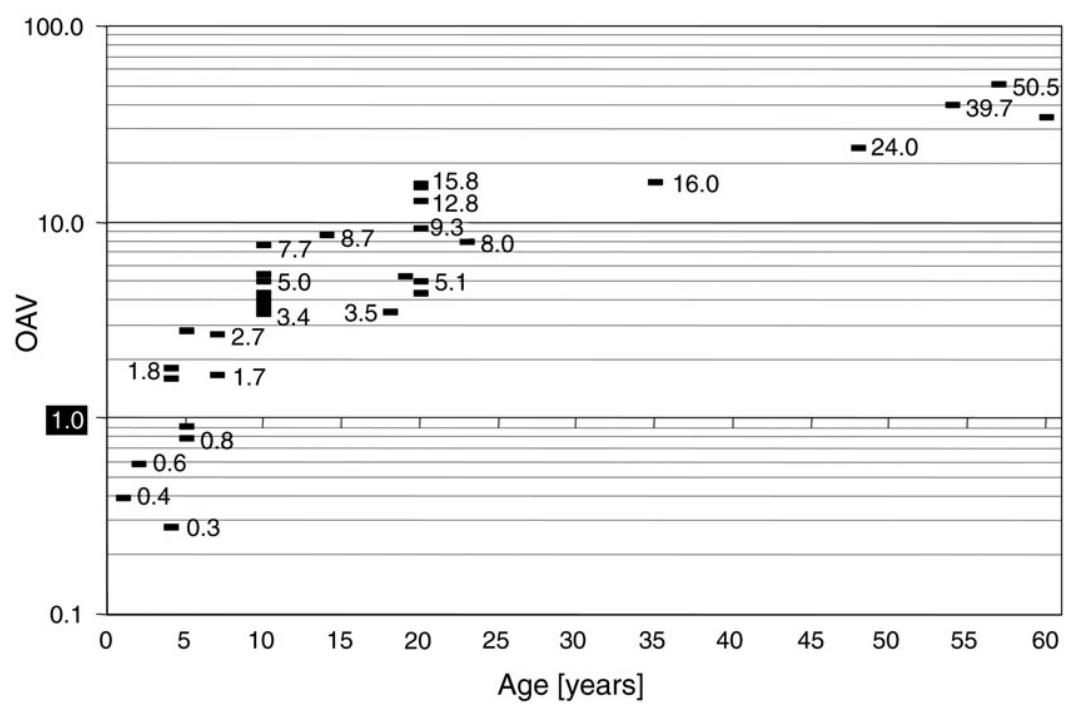

Fig. 3. Plot of the logarithm of $O A V$ in function of age ('Fecher's Law')

The behavior shown in Fig. 3 is in agreement with the empirical observation in the port wine industry where the 'rancio' aroma constitutes a 'quality factor' for wines aged in barrels for more than ten years.

As we have just seen, AEDA makes it relatively easy to characterize compounds involved in aromatic extracts of wine flavor, provided they are representative of the original wine. To appreciate the impact of these compounds, their perception thresholds in wine must be determined. This is easy for compounds which are not systematically present in wine, such as substances that appear during ageing. This is also the case for flavor-specific substances of certain varieties and 'off-flavors'. On the other hand, it is extremely difficult to determine an odor threshold in a matrix that already contains the compound being tested. The following example using $\beta$-damascenone will demonstrate this phenomenon.

The Role of B-Damascenone in Wine Aroma - Depending on the matrix, the odor threshold for $\beta$-damascenone can be quite diverse (Table 1 ).

Table 1. $\beta$-Damascenone Odor Thresholds [ng/l]

\begin{tabular}{lllll}
\hline $\mathrm{H}_{2} \mathrm{O} /$ EtOH soln. & Model white wine & Model red wine 1 & Model red wine 2 & Red wine \\
\hline 50 & 140 & 2100 & 850 & 7000 \\
\hline
\end{tabular}

In agreement with previous studies [18][20], the odor threshold of $\beta$-damascenone in hydro-alcoholic solution was very low, only $50 \mathrm{ng} / \mathrm{l}$, while it was three times higher in 
model white wine, 15 to 42 times higher in model red wine, and 140 times higher $(7 \mu \mathrm{g} / \mathrm{l})$ in red wine. The same kind of variation in odor threshold was previously reported for another $C_{13}$-norisoprenoid compound in red wines [19]. These authors demonstrated that the odor threshold varied depending on the initial concentration of the compound in the matrix. Moreover, the values obtained in their experiments were recognition thresholds, which are usually higher than their corresponding perception thresholds. They indicated that it was extremely difficult to determine an odor threshold in a matrix that already contained the compound being tested. In that case, the odor threshold may be considered a maximum value, even though concentrations used in ranking tests took the initial concentration into account. The odor threshold $(7 \mu \mathrm{g} / \mathrm{l})$ for the red wine that initially contained $400 \mathrm{ng} / \mathrm{l}$ of $\beta$-damascenone was certainly overestimated. In other words, the $\beta$-damascenone odor threshold in a red wine should be below $7 \mu \mathrm{g} / \mathrm{l}$. On the contrary, as the model base red and white wines contained no $\beta$-damascenone, they were far from being representative of the original wines, and could be regarded as almost hydro-alcoholic solutions. This was particularly true for model white wine and model red wine 2 , which were aromatically neutral. The odor thresholds obtained $(0.14,0.85$, and $2.1 \mu \mathrm{g} / \mathrm{l})$ may thus be considered minimum values. Consequently, the odor threshold of $\beta$-damascenone in red wine is probably above $2.1 \mu \mathrm{g} / \mathrm{l}$, and certainly above $0.85 \mu \mathrm{g} / \mathrm{l}$. Therefore, the odor threshold of $\beta$ damascenone in red wine is probably somewhere between 2 and $7 \mu \mathrm{g} / \mathrm{l}$.

Moreover, from an organoleptic point of view, the odor thresholds obtained apparently correlated with the fruity complexity of the matrix used. On a scale of increasing aromatic complexity, the very neutral model white wine was followed by model red wine 2 , with very little fruity character compared to model red wine 1 with its strong caramel and candied-fruit aromas. The odor thresholds determined showed exactly the same increasing scale. Thus, even in matrices without any trace of $\beta$ damascenone, the odor threshold increases with the complexity of the matrix.

Table 2 presents concentrations of the free $\beta$-damascenone and the $\beta$-damascenone precursors obtained in whole wines analyzed by GC/MS. Generally, the results show contents close to $1 \mu \mathrm{g} / \mathrm{l}$ for both free $\beta$-damascenone and $\beta$-damascenone precursors (on average $998 \pm 460$ and $812 \pm 491 \mu \mathrm{g} / \mathrm{l}$, resp.). Values for Bordeaux wines (the first nine wines in Table 2) were in the same range as previously reported [24][27].

Considering the perception-threshold range for $\beta$-damascenone and the levels assayed in wines, none of the wines tested had a sufficiently high concentration of $\beta$ damascenone to be perceptible in their aroma. Furthermore, the distinct apple aroma of $\beta$-damascenone was not recognized or identified in these red wines.

It might be possible that hydrolyzable precursors increase the concentration of free volatile $\beta$-damascenone in wines. Nevertheless, this point remains debatable, as, until now, no precise data on changes in $\beta$-damascenone concentrations in red wines have been available. Like all glyco-conjugated precursors, $\beta$-damascenone precursors may be hydrolyzed under acidic conditions during wine aging and storage, thus increasing the free $\beta$-damascenone concentration [18][29][30]. However, upon aging, $\beta$ damascenone may also be oxidized into the odorless hydroxy- $\beta$-damascone [18], thus reducing the free $\beta$-damascenone concentration. Moreover, $\beta$-damascenone may react with free $\mathrm{SO}_{2}$ to give the respective odorless carbonyl bisulfite, and thus the level of free $\mathrm{SO}_{2}$ may also influence the contribution of $\beta$-damascenone to the aroma of wine. The 
Table 2. Free $\beta$-Damascenone, $\beta$-Damascenone Precursor, and Total $\beta$-Damascenone Concentrations [ng/l] Obtained by GC/MS

\begin{tabular}{|c|c|c|c|c|c|c|}
\hline Origin & Wine & Vintage & Varieties & $\begin{array}{l}\text { Free } \beta \text { - } \\
\text { damascenone }\end{array}$ & $\begin{array}{l}\beta \text {-Damascenone } \\
\text { precursors }\end{array}$ & Total \\
\hline \multirow[t]{9}{*}{ Bordeaux } & A & 2002 & Merlot & 1042 & 1933 & 2975 \\
\hline & B & 2002 & & 1070 & 1781 & 2851 \\
\hline & $\mathrm{C}$ & 2002 & & 787 & 1458 & 2245 \\
\hline & $\mathrm{D}$ & 2002 & Cabernet Franc & 1356 & 914 & 2270 \\
\hline & $\mathrm{E}$ & 2002 & & 1357 & 1317 & 2674 \\
\hline & $\mathrm{F}$ & 2002 & & 977 & 943 & 1920 \\
\hline & G & 2002 & Cabernet Sauvignon & 1367 & 1001 & 2368 \\
\hline & $\mathrm{H}$ & 2002 & & 1711 & 1328 & 3039 \\
\hline & I & 2002 & & 1560 & 551 & 2111 \\
\hline \multirow[t]{3}{*}{ Rhône } & 7 & 2002 & - & 545 & 705 & 1250 \\
\hline & 8 & 2002 & $\begin{array}{l}\text { Grenache, Syrah, } \\
\text { Mourvèdre }\end{array}$ & 995 & 769 & 1764 \\
\hline & 16 & 2001 & & 714 & 149 & 863 \\
\hline \multirow[t]{2}{*}{ Burgundy } & 13 & 2002 & Pinot Noir & 471 & 448 & 919 \\
\hline & 14 & 2002 & Pinot Noir & 242 & 367 & 609 \\
\hline \multirow[t]{3}{*}{ Loire } & 10 & 2002 & Gamay & 845 & 264 & 1109 \\
\hline & 11 & 2002 & - & 740 & 367 & 1107 \\
\hline & 12 & 2002 & Gamay & 598 & 216 & 814 \\
\hline \multirow[t]{2}{*}{ Provence } & 1 & 1999 & - & 745 & 660 & 1405 \\
\hline & 9 & 2002 & - & 1042 & 823 & 1865 \\
\hline \multirow{4}{*}{$\begin{array}{l}\text { Languedoc } \\
\text { Roussillon }\end{array}$} & 2 & 2001 & - & 2307 & 911 & 3218 \\
\hline & 3 & 2001 & - & 801 & 912 & 1713 \\
\hline & 4 & 2002 & - & 593 & 606 & 1199 \\
\hline & 17 & 2002 & Merlot & 1092 & 254 & 1346 \\
\hline
\end{tabular}

total amount of free $\beta$-damascenone and $\beta$-damascenone precursors gives, therefore, only an approximation of the maximum potential $\beta$-damascenone concentration, if the entire amount of precursors were hydrolyzed without any further degradation and without reaction with $\mathrm{SO}_{2}$. Even taking the total amount into account, concentrations were generally closer to $2 \mu \mathrm{g} / \mathrm{l}(1810 \pm 789 \mathrm{ng} / \mathrm{l}$, on average $)$, i.e., lower than, or, in the best case, equal to the $\beta$-damascenone odor threshold in red wine. This data may appear to contradict the latest results on the impact of $\beta$-damascenone on wine aroma. The most recent publications [14][15][31][32] highlighted high OAV of $\beta$-damascenone and suggested that this compound had a direct contribution to the variety of aromas of red wines. According to Guadagni et al. [33], who first defined it, the OAV of an aromatic volatile corresponds to the ratio of the concentration of an aromatic volatile in a given matrix and the odor threshold of that volatile in the same matrix. However, the 'wine' matrix was not taken into account in previous OAV calculations. In fact, the $\beta$-damascenone content in wine was divided by the odor threshold of $\beta$-damascenone in water or hydro-alcoholic solution. Thus, OAVs obtained is this way were not really OAVs as defined by Guadagni et al. [33]. As demonstrated above, odor thresholds determined in solutions are very different from those in wine, so conclusions based on the OAV calculated using the odor threshold of $\beta$-damascenone in $\mathrm{H}_{2} \mathrm{O}$ or in the model 
base wine are unlikely to be very accurate. Thus, the potential direct impact suggested in various articles [14-17][31][32] is probably highly overestimated.

AEDA of wine extract showed that $\beta$-damascenone was detected at one of the highest dilution factors. It was perceived until the third or fourth dilution of the extract, as shown in Table 3. Dilutions of pure $\beta$-damascenone demonstrated that this volatile was detectable by $\mathrm{GC}-\mathrm{O}$ at concentrations as low as $5 \mu \mathrm{g} / \mathrm{l}$. Considering the volume injected $(2 \mu \mathrm{l}), 0.01 \mathrm{ng}$ of $\beta$-damascenone was detected in $\mathrm{GC}-\mathrm{O}$ analyses, a similar quantity to the $0.046 \mathrm{ng}$ reported in [34]. Furthermore, a wine extract may contain $\beta$-damascenone in a 90-fold higher concentration than the initial wine sample, depending on the procedures of sample preparation. Considering the concentration factor, it was logical that $\beta$-damascenone would be detected in the first three or four dilutions of the extracts, but not in the fifth, as shown in Table 3. $\beta$-Damascenone was only detected by AEDA in wine extracts or dilutions of wine extracts where the estimated concentration was above the $5 \mu \mathrm{g} / \mathrm{l}$ detection threshold. The question whether $\beta$-damascenone concentrations detected in wine extract are representative of wine aroma may be explored by comparing the odor and detection thresholds obtained in wine and $\mathrm{GC}-\mathrm{O}$, respectively. In fact, the $5 \mu \mathrm{g} / \mathrm{l}$ detection threshold obtained by $\mathrm{GC}-\mathrm{O}$ corresponds to a $\beta$-damascenone concentration of $c a .50-60 \mathrm{ng} / \mathrm{l}$ in wine, i.e., considerably lower than the odor thresholds obtained in model red wines and, a fortiori, in red wine. Contrary to findings in previous research, the major impact of $\beta$ damascenone as indicated in the $\mathrm{GC}-\mathrm{O}$ analysis of wine extract does not necessarily reflect its true contribution to the aroma of the original wine. In fact, even though AEDA is a very good method for a first investigation, it does not allow the extrapolation of the organoleptic impact of an aromatic compound from an analytical detection threshold. Generally, the major impact of $\beta$-damascenone in AEDA only reflects its very low detection threshold in $\mathrm{GC}-\mathrm{O}$, and, even if only imperceptible concentrations are present in red wines, this may be one of the preponderant compounds identified in olfactometric analyses.

Table 3. Average Estimated $\beta$-Damascenone Concentrations in Wine Extracts Analyzed by AEDA

\begin{tabular}{lcc} 
& Merlot $^{\mathrm{a}}$ ) & Cabernet franc $^{\mathrm{a}}$ ) \\
\hline Wine: GC/MS assay & 1.042 & 0.977 \\
Extract: $90 \times[$ Wine] & $\left.93.78^{\mathrm{b}}\right)$ & 87.93 \\
Dilution 1: [Extract]/2 & 46.89 & 43.97 \\
Dilution 2: [Dilution 1]/2 & 23.45 & 21.98 \\
Dilution 3: [Dilution 2]/2 & 11.72 & 10.99 \\
Dilution 4: [Dilution 3]/2 & 5.86 & 5.50 \\
Dilution 5: [Dilution 4]/2 & 2.93 & 2.75 \\
\hline
\end{tabular}

a) Concentrations in $\mu \mathrm{g} / \mathrm{l}$. ${ }^{\mathrm{b}}$ ) Grey squares: wine extracts or dilutions of wine extracts where $\beta$ damascenone was detected

This work on $\beta$-damascenone has contributed to identifying the limitations of AEDA in explaining wine flavors. Another, more time-consuming and complex method consists of identifying compounds responsible for particular odor-active zones previously highlighted by olfactometry. However, irrespective of the chromatographic 
conditions, when these analyses are applied to crude extracts, their complexity leads to co-elution phenomena, which makes the interpretation of these results extremely difficult. It was, therefore, necessary to add at least one further step to simplify the medium. We developed an HPLC fractionation method for crude organic extracts to avoid these problems.

HPLC Fractionation and Characterization of Volatiles $-C_{18}$ HPLC Fractionation was applied to red Bordeaux wines, previously selected for their typical fruitiness. Sensory evaluation of both wines and fractions confirmed the good preservation of aroma characteristics as shown in Table 4.

Table 4. Odor Description of Two Red Wines and of Fruity Fractions Obtained from Their Extracts

\begin{tabular}{lll} 
& Merlot & Cabernet Sauvignon \\
\hline Wine & caramel, fresh cherry & blackcurrant, black fruits liquor, spicy \\
F 5 & caramel & - \\
F & peach, pear & fatty, cheese \\
F16 & vinegar, winy & - \\
F17 & heavy, winy & banana, chemical \\
F18 & chemical, strawberry fruits, spicy \\
F19 & light black fruits & chemical, strawberry \\
F20 & fresh cherry, blackberry & light red fruits \\
F21 & light black fruits & intense blackcurrant \\
F22 & & fresh, spicy \\
\hline
\end{tabular}

For example, the Cabernet Sauvignon with specific aromas of blackcurrants, blackberries, blueberries, and spices gave three fractions with the corresponding aromas (18, featuring black berry-fruit and spices, 21 redolent of blackcurrant, and finally 22 smelling of spices). Extracts of the blend of fruity fractions were analyzed by both GC-O and GC/MS. Twelve ethyl esters and acetates, already known for their redfruit characteristics, were identified and have been described in [35]. Among these esters, higher concentrations in ethyl propanoate, ethyl 2-methylpropanoate, and ethyl 2-methylbutanoate were apparently linked to blackberry and blackcurrant aromas of the three ethyl esters. The impact of these compounds on the aroma of red wine was then investigated through reconstitution tests as shown in Table 5. De-aromatized red wine, without any fruity aroma, was supplemented with each ester to obtain the average

Table 5. Perception Thresholds in Red Wine and Levels Used in Reconstitution Tests for Ethyl Propanoate $\left(\mathrm{C}_{3} \mathrm{C}_{2}\right)$, Ethyl 2-Methylpropanoate $\left(2 \mathrm{MeC}_{3} \mathrm{C}_{2}\right)$, and Ethyl 2-Methylbutanoate $\left(2 \mathrm{MeC}_{4} \mathrm{C}_{2}\right)$

\begin{tabular}{|c|c|c|c|c|}
\hline & & $\mathrm{C}_{3} \mathrm{C}_{2}$ & $2 \mathrm{MeC}_{3} \mathrm{C}_{2}$ & $2 \mathrm{MeC}_{4} \mathrm{C}_{2}$ \\
\hline Initial content & & 13 & 16 & 2 \\
\hline \multirow[t]{4}{*}{ Content after addition $[\mu \mathrm{g} / \mathrm{l}]$} & test 1 & 80 & & \\
\hline & test 2 & & 40 & \\
\hline & test 3 & & & 5 \\
\hline & test 4 & 80 & 40 & 5 \\
\hline \multicolumn{2}{|c|}{ Perception threshold in red wine $[\mu \mathrm{g} / 1]$} & 2100 & 5600 & 1830 \\
\hline
\end{tabular}


concentration in red wine. Test by test, each ester was then individually added at the maximum values observed in red Bordeaux wines. A mixture of the three esters was also tested (test 4, Table 5).

Except for ethyl 2-methylbutanoate, the results showed a very clear individual impact for each ester in the model solution with a level of recognition of $72 \%$ for ethyl propanoate, $67 \%$ for ethyl 2-methylpropanoate, and $78 \%$ for the mixture of the three esters. The most interesting result was that variations in the concentrations of certain esters, even well below their perception thresholds, as low as $1-3 \%$, may impact the aroma of a wine.

Conclusions - It is very difficult to characterize the compounds responsible for wine flavor, mainly due to the complexity of the matrix, the particularly low concentrations involved, and the behavior of some of the compounds involved. The methodology begins with an extraction phase to extract relevant compounds in sufficient quantity for later analysis.

The second phase focuses on a potentially interesting odor-active zone. AEDA may be used but, as we have shown, it does not always give satisfactory results. Problems with the qualitative and quantitative representativeness of the flavor of the wine extract compared to the wine itself are a potential source of error. When this technique does not give satisfactory results, or the targeted flavors are not among the most highlyranked, it is necessary to track the aromatic components concerned throughout the analysis process. With some luck, this can be achieved simply by GC-O analyses of crude extracts. In most cases, however, considerable work is required in sample preparation, such as the HPLC technique presented here, to obtain a distinct odoractive zone. In some cases, the task is further complicated by the fact that the odor of a compound in solution and in olfactometric analyses is not the same.

Once the odor-active zone has been obtained, an analytical detector should be able to give a signal corresponding to the identified aroma. It is often necessary to optimize the separation technique, for example, by purifying the organic extract injected or using two-dimensional GC, to avoid co-elution problems. However, in many cases, it is not possible to obtain sufficiently concentrated extracts for correct identification.

Once the potential compound has been identified, its impact on the aroma has to be checked, initially by comparing the concentration present with its perception threshold. It is important, although by no means always easy, to determine this threshold in wine, as this is the only way to really estimate its direct effect.

Even at concentrations below the perception threshold, a compound may affect the aroma of wine indirectly, for example, by acting as a flavor enhancer, as we showed with $\beta$-damascenone for fruity flavors [36]. Various types of interactions between compounds in wine have many different effects and research has barely started in this fascinating area.

\section{Experimental Part}

Wine Material. Thirty-five samples of a single harvest ranging from 1- to 60-year-old 'Colheitas' port wine aged in barrels were supplied by the Instituto do Vinho do Porto (IVP) after certification. Twentythree red wines were used in the study concerning $\beta$-damascenone. Nine were selected to be 
representative of the Bordeaux region's diversity of soils and grape varieties (i.e., single-variety wines from vintage 2002 from Vitis viniferas L. var. Merlot, Cabernet Sauvignon, and Cabernet Franc, cultivated on three different soils (gravel, clay, and sand) and 14 others were selected to be representative of the diversity of red varieties grown in France as listed in Table 1.

Chemicals and Solvents. All the chemicals and solvents used were of anal. quality. $\mathrm{Et}_{2} \mathrm{O}, \mathrm{EtOH}$, and hexane were purchased from $V W R$ (Fontenay-sous-bois, France) and $\mathrm{CH}_{2} \mathrm{Cl}_{2}$ from $S D S$ (Peypin, France). $\beta$-Damascenone was obtained from Fluka (CH-Buchs), while ethyl-4-acetylbenzoate $(99 \%)$, 4,5-dimethyl-3-hydroxyfuran-2(5H)-one (97\%), and octan-3-ol $(99 \%)$ were purchased from SigmaAldrich (Saint Quentin Fallavier, France). XAD-2 (Amberlite $\left.{ }^{\circledR}\right)$ Resin from Supelco (Bellefonte, USA), and micro-filtered $\mathrm{H}_{2} \mathrm{O}$ (resistivity $18.2 \mathrm{M} \Omega \mathrm{cm}$ ) was used.

Panel of Sensory Studies. The sensory panel consisted of $c a$. 50 students, who received weekly training sessions. Tests were performed at a controlled r.t. of $20^{\circ}$, in individual booths, using covered AFNOR (Association Française des Normes) glasses, containing ca. $40 \mathrm{ml}$ liquid.

Descriptor Selection. The old port wine descriptor selection was effectuated by the panel using different barrel aged wines belonging to the 'tawny' category of '40 year-old'. The AFNOR NFV-09-021 procedure was used to select the most important descriptors related to the typical aroma of aged wines. In a first set of sessions, every member of the panel was asked to freely describe the aroma of the wine. The hedonic and redundant terms, as well as the non-pertinent terms, were then disregarded, and a first group of descriptors was obtained in this manner. Then, the panel was asked to determine if the first series of descriptors were present or absent. Those descriptors considered as absent by $50 \%$ of the panel were eliminated, and a second group was obtained. The panel was then asked to rank each descriptor belonging to this group on a scale of 0 to 10 .

Organic Extract Selection-Aroma Representation. A 40-year-old port wine was extracted with different org. solvents (hexane, $\mathrm{Et}_{2} \mathrm{O}, \mathrm{AcOEt}$, and $\mathrm{CH}_{2} \mathrm{Cl}_{2}$ ). Similarity tests were performed between the aroma of the obtained extracts and the wine. Two 2-ml samples of each org. extract were concentrated under a $\mathrm{N}_{2}$ stream to $0.5 \mathrm{ml}$. A drop was then put onto 'perfume sampling papers,' and the aroma was compared with the original wine. The data obtained were treated according to the ANOVA procedure.

Gas Chromatography-Olfactometry. GC-O analyses were carried out under the same conditions as the GC/MS analyses, but with an initial temp. of $45^{\circ}$ in the oven program and an olfactometric detection system. The make-up gas on the olfactometric device was air $\left(80 \% \mathrm{~N}_{2} ; 20 \% \mathrm{O}_{2}\right.$, Air Liquide, France). All $\mathrm{GC}-\mathrm{O}$ analyses were performed by a panel of three trained judges using the same operational conditions on the same gas chromatograph. The odor zones reported by each panel member were compared for each retention index. The descriptors were selected according to their frequency of citations. Hedonic terms were not considered (good/bad). Those considered to be analogues were replaced by the most cited.

Aroma Extract Dilution Analysis (AEDA). Dilution factors (DF) of wine extracts were determined by AEDA as described in [2]. Two $\mu$ l of concentrated extract used for quantification was separated on a cap. column, and the odor-active regions were evaluated by three different trained judges. The extracts were diluted stepwise with solvents they constituted of $(1: 1(v: v))$, and aliquots of the dilutions were evaluated by each of the same judges. The process stopped when the aroma was no longer detected. The same dilution method, applied to a pure $\beta$-damascenone soln. in $\mathrm{Et}_{2} \mathrm{O} / \mathrm{hexane} 1: 1(v / v)$, was used to determine the minimum quantity of $\beta$-damascenone perceived under these anal. conditions.

Thresholds Evaluation. Olfactory odor thresholds were measured using ranking tests, with series of triangle tests presented following increasing content. In each triangle test, the jury tested three samples: one containing the target compound dissolved in the matrix, while the other two consisted of the matrix alone. In another triangle test, the presentation was reversed. Thresholds were determined from the analysis of individual thresholds by the judges. The individual odor threshold of each judge corresponds to the first concentration from which on all his triangular tests were valid. Compiling these results, a detection rate is calculated for each concentration tested. This corresponds to the percentage of judges whose individual odor threshold is inferior or equal to the concentration considered. A graph is then established with the detection rates obtained for each concentration. The odor threshold is finally determined extrapolating from this graph the concentration corresponding to a $50 \%$ perception rate of the judges. 
Four odor thresholds were determined for $\beta$-damascenone, each using an increasing range of five or eight concentrations in different matrices, as summarized in Table 2. The hydro-alcoholic soln. was a $\mathrm{H}_{2} \mathrm{O} / \mathrm{EtOH}$ mixture $88: 12(v / v)$ with $4 \mathrm{~g} / \mathrm{l}$ tartaric acid, and $\mathrm{pH}$ was adjusted to $3.5(\mathrm{KOH}, 0.5 \mathrm{~N})$. Model white wine was prepared by mixing $1 \mathrm{~g}$ of charcoal with 11 of white wine (Chardonnay) for $48 \mathrm{~h}$ in a closed bottle. The mixture was then filtered to remove the charcoal, and the liquid was mixed with $1 \mathrm{~g}$ of charcoal for $24 \mathrm{~h}$, then filtered. The second step was repeated as many times as necessary to obtain a model white wine without any traces of $\beta$-damascenone (i.e., below $2 \mathrm{ng} / \mathrm{l}$ ). The whole operation was carried out under $\mathrm{N}_{2}$ to avoid oxidation of the wine. From an organoleptic point of view, model white wine smelled very neutral, without any fruity aroma. The red wine was a Merlot from the Languedoc region, with a $\beta$-damascenone concentration evaluated at $400 \mathrm{ng} / \mathrm{l}$. Concentrations used in ranking tests took the initial concentration into account. Two model red wines were obtained from the initial wine. Model red wine 1 was prepared by evaporating a red wine using a Rotavapor (Büchi, $\mathrm{CH}$ ), with a bath temp. of $20^{\circ}$. The viscous residue was washed with $25 \mathrm{ml}$ of $\mathrm{MeOH}$, then evaporated again. This step was repeated twice. Finally, a $\mathrm{H}_{2} \mathrm{O} / \mathrm{EtOH} 88: 12(v / v)$ mixture was added to the residue to reconstitute the initial volume of wine. Model red wine 2 was prepared by a $2 / 3$ evaporation of 1.51 of red wine (the same wine used to prepare model red wine 1). The liquid was then mixed with $180 \mathrm{ml}$ of abs. EtOH, and, finally, the mixture was diluted with Millipore MilliQ $\mathrm{H}_{2} \mathrm{O}$ to 1.51 . Analysis of model red wines 1 and 2 confirmed that the matrices contained no $\beta$-damascenone. From an organoleptic point of view, model red wine 2 was neutral, while model red wine 1 presented a caramel and candied fruit aroma.

Determining the threshold of Sotolon constituted a major difficulty in this study. In fact, adding this molecule to a young ( $<2$-year-old) port wine disrupted its typical aroma profile (floral, fruity...). In fact, above the recognition threshold the panel rated the samples as 'not-typical' aged wine. Contrarily, this was not a problem in old wines ( $>10$ years) due to the fact that this molecule its one of its typical constituents being present at concentrations above $50 \mu \mathrm{g} / \mathrm{l}$. Hence, a compromise solution was taken by selecting a 4-year-old wine to perform this study. In this sample, the quantities of Sotolon found were above the detection limit of the method, and the floral and fruity notes were rated as 'weak' by the panel.

Quantification of $\beta$-Damascenone in Wines. To extract free $\beta$-damascenone, $50 \mathrm{ml}$ of wine was supplemented with $50 \mu \mathrm{l}$ of ethyl-4-acetylbenzoate in aq. alcoholic soln. $(1: 1(v / v))$ at $0.91 \mathrm{mg} / \mathrm{l}$ as internal standard. The wine was extracted at r.t., using 4, 2, and $2 \mathrm{ml}$ of $\mathrm{Et}_{2} \mathrm{O} /$ hexane 1:1 $(v / v)$, with magnetic stirring $(2000 \mathrm{rpm})$ for $5 \mathrm{~min}$. The three extracts were blended ( 5 to $6 \mathrm{ml}$ of total extract) and dried (anh. $\left.\mathrm{Na}_{2} \mathrm{SO}_{4}\right)$, concentrated tenfold under a $\mathrm{N}_{2}$ stream $(1 \mathrm{l} / \mathrm{min})$, and maintained at $-20^{\circ}$ until being analyzed.

Quantification of $\beta$-damascenone precursors was assayed as described in [37]. After isolation of the volatiles by liquid-liquid extraction (free $\beta$-damascenone extraction method), any trace of solvent was eliminated from the wine sample using a Rotavapor for 10 to $15 \mathrm{~min}$ (bath temp. $25^{\circ}$ ).

Isolation of $\beta$-damascenone precursors was then performed by a solid-liquid extraction on XAD-2 resin $\left(\right.$ Amberlite $\left.^{\circledR}\right)$. Nine $\mathrm{ml}$ of resin were put in a column (internal diameter: $1.5 \mathrm{~cm}$, length: $20 \mathrm{~cm}$ ) and conditioned with $60 \mathrm{ml}$ of $\mathrm{MeOH}, 60 \mathrm{ml}$ of $\mathrm{Et}_{2} \mathrm{O}$, and $60 \mathrm{ml}$ of Millipore MilliQ $\mathrm{H}_{2} \mathrm{O}$, successively. The wine sample was then loaded, followed by $120 \mathrm{ml}$ of dist. $\mathrm{H}_{2} \mathrm{O}$. Precursors were finally eluted from the resin with $50 \mathrm{ml}$ of $\mathrm{MeOH}$ (all liquids were loaded at a flow rate of $c a .2 .5 \mathrm{ml} / \mathrm{min}$ ). The $\mathrm{MeOH}$ extract was evaporated to dryness using a rotavapor (bath temp. $25^{\circ}$ ). The residue was taken up in $20 \mathrm{ml}$ of a citric acid buffer $(0.1 \mathrm{~N})$, sealed under $\mathrm{N}_{2}$ atmosphere in a $25 \mathrm{ml}$ glass ampoule, and hydrolyzed at $100^{\circ}$ for $1 \mathrm{~h}$ to generate hydrolytically released $\beta$-damascenone. The sample was allowed to cool to r.t., and $24 \mathrm{ml}$ of Millipore MilliQ $\mathrm{H}_{2} \mathrm{O}$ and $6 \mathrm{ml}$ of EtOH were added to restore the 50-ml sample, from which hydrolytically released $\beta$-damascenone had been extracted using the free $\beta$-damascenone extraction method.

The extract $(2 \mu \mathrm{l})$ was then injected into the GC/MS apparatus. Chromatographic conditions were as follows: Hewlett-Packard HP 6890 gas chromatograph coupled with a mass spectrometer (HP 5973); electron impact $70 \mathrm{eV}$; selected ion monitoring (SIM) detection mode with $\mathrm{m} / z 121$ (internal standard and $\beta$-damascenone quantification) and $m / z 177$ ( $\beta$-damascenone qualification) ions; BP20 (SGE) column, $50 \mathrm{~m} \times 0.25$-mm i.d., 0.25 - $\mu \mathrm{m}$ film thickness; He $5.6 \mathrm{Aga}^{\circledR}$ pressure: $55 \mathrm{kPa}$; injector temp.: $220^{\circ}$; detector temp.: $250^{\circ}$; oven temp.: $40^{\circ}$ for $1 \mathrm{~min}$ programmed at a rate of $3 \% \mathrm{~min}$ to $230^{\circ}$, the final step lasting $15 \mathrm{~min}$; splitless time, $30 \mathrm{~s}$; split flow, $30 \mathrm{ml} / \mathrm{min}$. 
Intralaboratory reproducibility was determined by ten successive analyses of the same red wine containing $400 \mathrm{ng} / \mathrm{l}$ of $\beta$-damascenone, and the variation coefficient was $0.76 \%$, which is quite similar to the $0.8 \%$ obtained with labelled $\beta$-[ $\left[\mathrm{D}_{4}\right]$ damascenone [38]. The linearity of the method was evaluated by adding $\beta$-damascenone $(0,100,200,400,800,1600$, and $3200 \mathrm{ng} / \mathrm{l})$ to the same red wine initially containing $400 \mathrm{ng} / \mathrm{l}$ of $\beta$-damascenone. The correlating coefficient between found and added levels was $r=0.9991$.

Quantification of 3-Hydroxy-4,5-dimethylfuran-2(5H)-one. To $50 \mathrm{ml}$ of wine was added $50 \mu \mathrm{l}$ of octan-3-ol in hydro-alcoholic soln. $(1: 1(v / v))$ at $432.9 \mathrm{mg} / \mathrm{l}$ as internal standard and $5 \mathrm{~g}$ of anh. $\mathrm{Na}_{2} \mathrm{SO}_{4}$. The wine was extracted twice with $5 \mathrm{ml}$ of $\mathrm{CH}_{2} \mathrm{Cl}_{2}$. The two org. layers obtained were blended and dried $\left(\mathrm{Na}_{2} \mathrm{SO}_{4}\right)$. Two $\mathrm{ml}$ of this org. soln. was concentrated five times under a $\mathrm{N}_{2}$ stream with a $1 \mathrm{l} / \mathrm{min}$ gas flow. Two $\mu \mathrm{l}$ of this extract was injected into the GC/MS apparatus. Chromatographic conditions were as follows: Hewlett-Packard HP 5890 gas chromatograph coupled with a mass spectrometer (HP 5972; electron impact $70 \mathrm{eV} ; \mathrm{EMV}=2.2 \mathrm{kV}$; detection mode was selected ion monitoring (SIM) with ion of $m / z$ 83; column BP21 (SGE, France, $50 \mathrm{~m} \times 0.25 \mathrm{~mm}, 0.25 \mu \mathrm{m}$ ); He $5.6 A g a^{\circledR}$ pressure: $55 \mathrm{kPa}$; injector temp.: $220^{\circ}$; detector temp.: $280^{\circ}$; oven temp.: $40^{\circ}$ for $1 \mathrm{~min}$ programmed at a rate of $2 \% \mathrm{~min}$ to $220^{\circ}$, the final step lasting $30 \mathrm{~min}$; splitless time, $30 \mathrm{~s}$; split flow, $30 \mathrm{ml} / \mathrm{min}$. The reproducibility of the method was calculated from ten analyses of a wine containing $91.6 \mu \mathrm{g} / \mathrm{l}$ of Sotolon. The variation coefficient was found to be $4.98 \%$. The linearity of the method was tested using a young port wine as matrix; the quant. analysis of Sotolon additions showed that the method was linear for this compound with satisfactory precision. The concentrations range tested over seven Sotolon additions was between 4.1 and $810 \mu \mathrm{g} / \mathrm{l}$, and the correlation coefficient between levels added and levels assayed was $r=0.9998$.

Preparation of Wine Extracts and Anal. Conditions of HPLC Assays. The wine $(500 \mathrm{ml})$ was extracted using 100,50 , and $50 \mathrm{ml} \mathrm{CH}_{2} \mathrm{Cl}_{2}$, with magnetic stirring (500 rpm) for $5 \mathrm{~min}$. The three extracts were blended, dried (anh. $\left.\mathrm{Na}_{2} \mathrm{SO}_{4}\right)$, and concentrated to obtain $1 \mathrm{ml}$ of wine extract. Normal phase (NP) HPLC was performed with $\mathrm{NH}_{2}$ column, and reversed phase (RP) HPLC were performed with $C 8$ and C18 columns. All columns were from Waters, $30-\mathrm{cm}$ long and 3.9-mm i.d. Chromatographic conditions were optimized as follows: flow rate, $0.5 \mathrm{ml} / \mathrm{min}$; injection volume: $256 \mu \mathrm{l}$ of wine extract; program gradient: phase $A$, pentane (NP-HPLC) or $\mathrm{H}_{2} \mathrm{O}$ (RP-HPLC); phase $\mathrm{B}, \mathrm{CH}_{2} \mathrm{Cl}_{2}$ (NP-HPLC) or EtOH (RP-HPLC); $\min 0-2,100 \% A$, linear programmed until $100 \% B$ in min 50 . The effluent was collected in $1-\mathrm{ml}$ fractions. Twenty-five fractions in hydro-alcoholic solns. were obtained this way, and then directly evaluated by a panel of three trained judges to retain fruity fractions.

\section{References}

[1] T. E. Acree, J. Barnard, D. G. Cunningham, in 'Analysis of Volatiles', Ed. P. Schreier, de Gruyter, New York, 1984.

[2] F. Ullrich, W. Grosch, Z. Lebensm.-Unters.-Forsch. 1987, 184, 277.

[3] P. Pollien, A. Ott, F. Montigon, M. Baumgartner, R. Munoz-Box, A. Chaintreau, J. Agric. Food Chem. 1997, 45, 2630

[4] V. Ferreira, J. Pet'ka, M. Aznar, J. Cacho, in 'The 10th Weurman Flavour Research Symposium 2528 June 2002', Beaune, France, 2002, p. 144.

[5] T. Hofmann, P. Schieberle, J. Agric. Food Chem. 1995, 43, 2187.

[6] T. Hofmann, P. Schieberle, J. Agric. Food Chem. 1997, 45, 898.

[7] I. Blanck, A. Sen, W. Grosch, Z. Lebensm.-Unters.-Forsch. 1992, 195, 239.

[8] H. Guth, W. Grosch, J. Agric. Food Chem. 1994, 42, 2862.

[9] P. Schnermann, P. Schieberle, J. Agric. Food Chem. 1997, 45, 867.

[10] H. Guth, J. Agric. Food Chem. 1997, 45, 3022.

[11] A. C. Silva Ferreira, T. Hogg, P. Guedes de Pinho, J. Agric. Food Chem. 2003, 51, 1377.

[12] E. Demole, P. Enggist, U. Sauberli, M. Stoll, E. Kovats, Helv. Chim. Acta. 1970, 53, 541.

[13] P. Schreier, F. Drawert, Z. Lebensm.-Unters.-Forsch. 1974, 154, 273.

[14] M. Aznar, R. Lopez, J. F. Cacho, V. Ferreira, J. Agric. Food Chem. 2001, 49, 2924.

[15] V. Ferreira, N. Ortin, A. Escudero, R. Lopez, J. F. Cacho, J. Agric. Food Chem. 2002, 50, 4048. 
[16] Y. Kotseridis, R. Baumes, J. Agric. Food Chem. 2000, 48, 400.

[17] R. Lopez, V. Ferreira, P. Hernandez, J. F. Cacho, J. Sci. Food Agric. 1999, 79, 1461.

[18] R. G. Buttery, R. Teranishi, L. C. Ling, J. G. Turnbaugh, J. Agric. Food Chem. 1990, 38, 336.

[19] Y. Kotseridis, R. Baumes, A. Bertrand, G. Skouroumounis, J. Chromatogr., A. 1999, 848, 325.

[20] R. Lopez, N. Ortin, J. C. Perez-Trujillo, J. F. Cacho, V. Ferreira, J. Agric. Food Chem. 2003, 51, 3419.

[21] R. Lopez, M. Aznar, J. F. Cacho, V. Ferreira, J. Chromatogr., A. 2002, 966, 167.

[22] I. Sabon, G. de Revel, Y. Kotseridis, A. Bertrand, J. Agric. Food Chem. 2002, 50, 6341.

[23] Y. Kotseridis, R. Baumes, G. Skouroumounis, J. Chromatogr., A. 1999, 849, 245.

[24] Y. Kotseridis, A. Anocibar-Beloqui, A. Bertrand, J. P. Doazan, Am. J. Enol. Vitic. 1998, 49, 44.

[25] R. F. Raffauf, T. M. Zennie, K. D. Onan, P. W. Le Quesne, J. Org. Chem. 1984, 46, 271.

[26] R. Lizarraga-Guerra, H. Guth, M. G. Lopez, J. Agric. Food Chem. 1997, 45, 1329.

[27] B. Martin, P. X. Etiévant, J. L. Le Quéré, P. Schlich, J. Agric. Food Chem. 1992, 40, 475.

[28] M. Masuda, E. Okawa, K. Nishimura, H. Yunome, Agric. Biol. Chem. 1984, 48, 2707.

[29] P. Winterhalter, M. A. Sefton, P. J. Williams, Am. J. Enol. Vitic. 1990, 41, 277.

[30] P. Winterhalter, M. A. Sefton, P. J. Williams, J. Agric. Food Chem. 1990, 38, 1041.

[31] V. Ferreira, R. Lopez, A. Escudero, R. F. Cacho, J. Sci. Food Agric. 1998, 77, 259.

[32] V. Ferreira, R. Lopez, R. F. Cacho, J. Sci. Food Agric. 2000, 80, 1659.

[33] D. G. Guadagni, R. G. Buttery, J. Harris, J. Sci. Food Agric. 1966, 17, 142.

[34] P. K. C. Ong, T. E. Acree, J. Agric. Food Chem. 1999, 47, 665.

[35] B. Pineau, Ph.D. Thesis, University Victor Segalen Bordeaux 2, 2007.

[36] B. Pineau, J.-C. Barbe, C. P. Van Leeuwen, D. Dubourdieu, J. Agric. Food Chem. 2007, 55, 4103.

[37] Y. Z. Günata, C. L. Bayonove, R. L. Baumes, R. E. Cordonnier, J. Chromatogr., A. 1985, 331, 83.

[38] Y. Kotseridis, R. Baumes, G. Skouroumounis, J. Chromatogr., A 1998, 824, 71. 